\title{
DERMOID CYST OF OVARY MISDIAGNOSED AS INTRAUTERINE FETAL DEMISE: A CASE REPORT
}

\author{
Varsha, Shanti Subedi, Anju Deo, Anjana Sharma, \\ and Sita Ghimire
}

\begin{abstract}
:
Thirty two years multipara with amenorrhoea of five months presented with bleeding per vagina for ten days. Clinically and radiologically she was diagnosed with intrauterine fetal demise at 20 weeks period of gestation. She was induced with prostaglandins continuously for seven days. On eighth day of admission features of uterine rupture was present. On laparotomy ruptured huge dermoid cyst with chemical peritonitis was discovered. There was no evidence of pregnancy. We are reporting this case for a rare complication of ruptured dermoid cyst and also to illustrate the importance of clinical assessment.
\end{abstract}

Keywords: intrauterine fetal demise, ruptured dermoid cyst, chemical peritonitis, ultrasound

\section{Introduction:}

Mature cystic teratoma (dermoid cyst) is one of the most common benign ovarian neoplasm discovered during pregnancy $(20-40 \%) .{ }^{1,2}$ They may be responsible for complications such as torsion and rupture. Rupture is rare, but once it has occurred it can cause complications such as chemical peritonitis. ${ }^{3-5}$ This case illustrates the unusual complication of ruptured dermoid cyst leading to peritonitis misdiagnosed as intrauterine fetal demise.

\section{Case report:}

A multiparous lady of 32 years with amenorrhoea of five months presented with bleeding per vagina for 10 days. Clinically on per abdomen examination 20 weeks size irregular mass was palpated. Ultrasound abdomen showed intrauterine fetal demise (fig.1). She was induced with prostaglandin continously for seven days. On eighth day of admission, patient developed abdominal distension and fetal parts could be palpated. Ultrasound revealed fetal parts outside the uterine cavity and free fluid with internal debris in the peritoneal cavity. With the provisional diagnosis of rupture uterus, exploratory laparotomy was performed. In per operative finding ruptured right ovarian dermoid cyst about $15 \mathrm{~cm} \times 15 \mathrm{~cm}$ (fig.2) and sebaceous marerial was seen in the peritoneal cavity. Left ovarian dermoid measuring $5 \times 5$ $\mathrm{cm}$ was present. Uterus was normal in size. As uterus and the adnexal structures was densely adhered and dissection of demoid cyst was difficult so total abdominal hysterectomy with bilateral salpingoophorectomy was done. On cut section no fetal parts was seen in the dermoid cyst. Uterine cavity and cervical canal was empty. Post surgery urinary pregnancy test was negative. Histopathology report showed mature cystic teratoma. The final diagnosis was ruptured dermoid cyst with chemical peritonitis.

\section{Discussion:}

This case of mature cystic teratoma was confused with pregnancy as patient presented with history of amenorrhoea. Ultrasound report showing intrauterine fetal demise misguided us. Clinically 20 weeks size mass was palpated per abdomen and at 20 weeks period of gestation urinary pregnancy test is usually not done. The complaint of the patient and characteristics of the mass such as position and consistency were confused with pregnancy. Bilateral dermoid cyst is present in 


\section{Case Report}

only $10-15 \%$ of the cases. Rupture of cyst before or during operation may lead to chemical peritonitis. The incidence of chemical peritonitis after rupture and leakage of cystic fluid is less than $0.5 \%{ }^{2}$ Clement et al and achtari et al reported chemical peritonitis following cystic fluid spillage. ${ }^{6,7} \mathrm{In}$ our case whether repeated dose of prostaglandin led to rupture of dermoid cyst is still controversial.

\section{Conclusion:}

Any abdominal mass should be thoroughly investigated. Ultrasound is not the only diagnostic tool. Clinical assessment is mandatory. Overemphasis on ultrasound sometimes gives erroneous impression leading to erroneous management of the case.

\section{References:}

1. Comerci JT Jr, Licciardi F, Bergh PA, Gregori C, Breen JL. Mature cystic teratoma: a clinicopathologic evaluation of 517 cases and review of the literature. Obstet Gynecol 1994;84:22-8.

2. Peterson WF, Prevost EC, Edmunds FT, Hundley JM Jr, Morris FK. Benign cystic teratomas of the ovary; a clinico-

statistical study of 1,007 cases with a

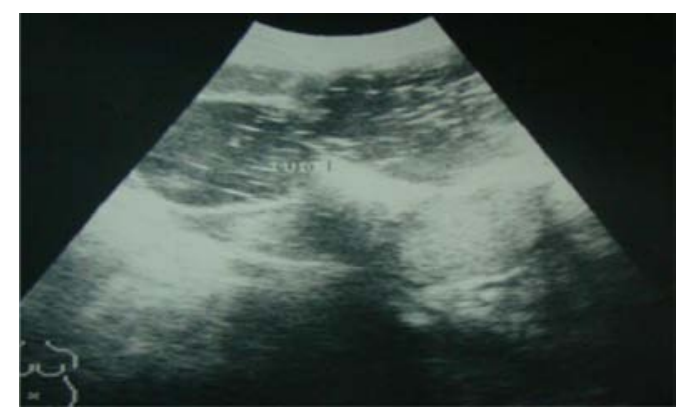

Fig.1. Ultrasound showing Intra uterine fetal death

\section{Misdiagnosis of Dermoid Cyst of Ovary}

review of the literature. Am J Obstet Gynecol 1955;70:368-82.

3. Stuart GC, Smith JP. Ruptured benign cystic teratomas mimicking gynecologic malignancy.Gynecol Oncol 1983;16:13943.

\section{Suprasert $\mathbf{P}$, Khunamornpong $\mathbf{S}$,} Siriaunkgul S, Phongnarisorn C, Siriaree S. Ruptured mature cystic teratomas Mimicking advanced stage ovarian cancer: a report of 2 case study. $\mathrm{J}$ Med Assoc Thai 2004;87(12):1522-5.

5. Phupong V, Sueblinvong T, Triratanachat S. Ovarian teratoma with diffused peritoneal reactions mimicking advanced ovarian malignancy. Arch Gynecol Obstet 2004:270:189-91.

6. Clement D, Barranger E, Benchimol Y, Uzan S. Chemical peritonitis: a rare complication of an iatrogenic ovarian dermoid cyst rupture. Surg. Endosc 2003;17:658.

7. Achtari C, Genolet PM, Bouzourene H, De Grandi P. Chemical peritonitis after iatrogenic rupture of a dermoid cyst of the ovary treated by coelioscopy. Apropos of a case and review of the literature.

GynakolGeburtshilfliche Rundsch 1998;38(3):146-50.

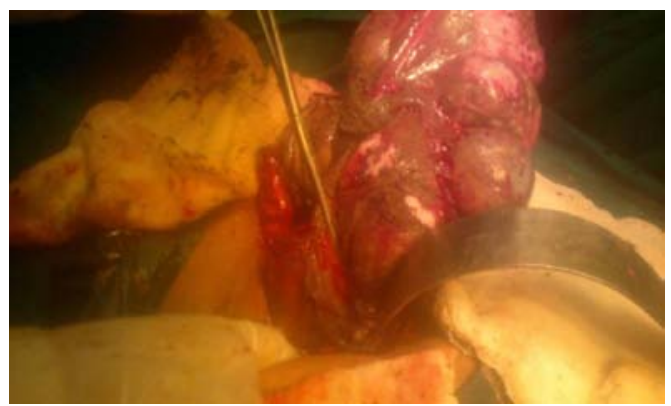

Fig.2. Left dermoid cyst of ovary

Correspondence Address: Varsha, Lecturer, Department of Obstetrics and Gynecology, Nobel Medical College, Biratnagar, Nepal. E-mail: varshanathani2008@yahoo.com 